\title{
PHENOTYPIC VARIATION IN A ZOOPLANKTON EGG BANK ${ }^{1}$
}

\author{
Nelson G. Hairston, Jr. and Colleen M. Kearns \\ Section of Ecology and Systematics, Cornell University, Ithaca, New York 14853-2701 USA
}

STEPHEN P. ElLner

Biomathematics Program, Department of Statistics, North Carolina State University, Raleigh, North Carolina 27695-8203 USA

\begin{abstract}
Dormant propagule pools may store potentially significant genetic variation that can influence the rate and direction of microevolution via directional selection, temporally fluctuating selection, and evolution of trait covariance between timing of emergence from the propagule pool and fitness characters expressed in the active population. The third process can interact with either of the first two to produce distinct effects. Each process can lead to a different distribution of genotypes and phenotypes between active and dormant subpopulations. We compared the phenotypic distributions of an important fitness character for individuals collected from active and diapausing subpopulations of a freshwater copepod, Diaptomus sanguineus, with a long-lived egg bank. The character, seasonal timing of the switch from production of immediately hatching eggs to diapausing eggs, determines the relative representation of copepods with different switch dates in future generations and is subject to fluctuating selection due to year-to-year changes in the timing and intensity of the seasonal onset of fish predation.

The mean timing of diapause is significantly later in the season for copepods reared from long-lived diapausing eggs than it is for copepods reared from individuals collected from the water column. Phenotypic variance for diapause timing does not differ between the two subpopulations. Within the sediment subpopulation, the distribution of diapause timing depends upon two features of the diapausing eggs: (1) individuals originating from eggs near the sediment surface exhibit a slightly earlier switch date with greater phenotypic variance than individuals from deep in the sediments, and (2) individuals from eggs that hatched shortly after they were collected from sediments have a later seasonal switch to diapause than those that hatched later in time. We hypothesize that our results are explained by adaptive covariance between traits that influences how long an egg spends in the sediments before hatching and traits that influence the seasonal timing of diapause. The covariance may result from either phenotypic plasticity or from genetic covariance between diapause timing and hatching probability.
\end{abstract}

Key words: copepod; diapause timing; diapausing eggs; Diaptomus sanguineus; dormant propagule pool; egg bank; evolution; fluctuating selection; photoperiod, diapause timing; temperature, diapause timing; trait covariance.

\section{INTRODUCTION}

An extraordinary diversity of organisms, including representatives from all kingdoms, produce long-lived dormant stages such as cysts, spores, seeds, or eggs capable of surviving for multiple years or decades (Hairston et al. 1996). In a few instances, survival for centuries or even millennia has been documented (Hairston et al. 1996). The effects of these dormant propagule pools on evolutionary dynamics within populations are likely to be substantial, particularly when the distribution of dormant genotypes is different from that in the active population. Three distinct effects have been identified in the theoretical literature. First, emergence of dormant stages may slow down response rate to directional selection by increasing average generation time (Templeton and Levin 1979, Brown and Venable 1986). Second, dormant propagule pools may act

\footnotetext{
' Manuscript received 21 June 1995; revised 8 March 1996; accepted 13 March 1996.
}

to maintain genetic variation when selection fluctuates through time by providing a mechanism of temporal bet hedging distinct from maximization of geometric mean fitness (Chesson 1984, Seger and Brockmann 1987, Ellner and Hairston 1994). Third, the duration of dormancy may itself evolve as a function of traits expressed in the active stage, which may in turn alter the direction or intensity of selection on the active traits (Brown and Venable 1986, Rees 1994).

Reciprocally, both directional and fluctuating selection should result in a gradual accumulation of genotypes in the dormant propagule pool that differ from those expressed in the active population at any one time. Directional selection should lead to the mean genotype in the propagule pool being different from that in the active population, whereas fluctuating selection, in contrast, should result in greater genotypic variance in the propagule pool than in the active population. In the case of evolution of covariance between dormancy duration with other traits, the effects on the distribution 
of genotypes must depend upon the specifics of the system. For example, Rees' (1994) suggestion that adult life span should covary negatively with duration of dormancy does not dictate any difference between the genotype distributions of the adult life span trait for active and dormant individuals. However, Evans and Cabin's (1995) proposal that "adaptive syndromes" associate genes for terminating dormancy in a particular type of year (i.e., environment) with genes for performance in that year type, should lead to greater genetic variation in the dormant pool than expressed at any one time in the active population.

Despite the potential evolutionary importance of prolonged dormancy, only a few studies have compared the genotypes or phenotypes of dormant propagules with active individuals from single populations. Most of the research in this area has been either with plant seed banks or with freshwater zooplankton egg banks. Dormant seeds may promote genetic constancy in annual plant populations (Epling et al. 1960, Gottlieb 1974), or similarly, zooplankton diapausing eggs may slow response to directional selection (Hairston and De Stasio 1988). Bosbach et al. (1982) found greater allozyme diversity in annual plant populations germinating from recently plowed soils than in those germinating on less disturbed sites and interpreted this as evidence for stored genetic variation in the seed bank. Comparisons of allozymic diversity between relatively shortlived (3-6 or 7 yr) seed banks and growing plants yield conflicting results. Tonsor et al. (1993) showed differences in allele frequencies but not in total genetic variance between the two components of the population, and concluded that the seed bank had little effect on microevolutionary dynamics in their population. In contrast, Evans and Cabin (1995) found substantial genetic differences between the germinated and dormant subpopulations, though their results were potentially confounded by spatial structure. Two investigations of zooplankton electrophoretic variation found no statistically significant differences in allozyme heterozygosity between water-column-derived and sedimentderived subpopulations (Wolf and Carvalho 1989; M. G. Boileau and N. G. Hairston, Jr., unpublished manuscript). It is not clear, however, what to conclude from these allozyme studies, whether plant or zooplankton. Though expectation of genetic differences between dormant propagules and active individuals in any given population is based on the proposition that selection is acting, electrophoretically identified genotypes are frequently assumed to be selectively neutral (e.g., Kimura 1983, Futuyma 1986). If they are neutral, year-to-year changes via genetic drift could still result in an accumulation of genetic variation in the dormant stages, but only when the population size of active, breeding individuals is small. This was distinctly not the case in any of the studies just cited.

Phenotypic characters of demonstrable fitness significance provide a better way to explore genetic dif- ferences between a dormant propagule pool and active members of a population. McGraw and his colleagues have provided the only investigations of this kind (Bennington et al. 1991, Vavrek et al. 1991, McGraw 1993). Capitalizing on the presence of viable plant seeds buried in arctic tundra for up to $150 \mathrm{yr}$ (McGraw et al. 1991), they compared various performance measures (e.g., plant size, growth rate, competitive ability) for three species. In each case, mean phenotype (and, presumably genotype) differed between seed-bank and active individuals. This suggests directional selection has taken place over the period from production of the oldest seeds to the present (Bennington et al. 1991, Vavrek et al. 1991, McGraw 1993). At the same time, it is interesting to note that although these investigators uncovered substantial phenotypic variance within the different subpopulations (seed bank vs. active), the absolute level of variation did not appear to be greater in the seed-bank-derived individuals than in the active ones for any of the species (although the authors did not discuss this comparison explicitly). This result suggests that neither fluctuating selection nor evolution of adaptive syndromes was important over the period studied, or that seeds, once buried in the permafrost, contributed little or nothing to future population dynamics. Evans and Cabin (1995), studying a desert annual plant, found that there was significant genetic variation for both tendency to germinate in different environments and for post-germination performance. They speculated that selection acting on both subpopulations could lead to the evolution of covariance between seed bank and post-germination traits.

An opportunity to explore variation stored in a dormant propagule pool is presented by a population of calanoid copepods, Diaptomus sanguineus, living in Bullhead Pond, a small lake in southern Rhode Island. This copepod population is active under the ice during winter when it makes eggs that hatch immediately. In spring each year, the copepods switch to making diapausing eggs (Hairston and Munns 1984). For this population, we know that the annual spring onset of fish predation acts as a selection force on the timing of diapause initiation (Hairston and Munns 1984, Hairston 1987), that onset of fish predation (and hence selection on optimal diapause timing) fluctuates between years (Hairston 1988), that diapause timing is heritable under both laboratory and field conditions (Hairston and Dillon 1990), and that the mean phenotype of the population shifts between years in response to selection (Hairston and Dillon 1990). In addition, the diapausing eggs produced by the copepods are present in high density $\left(>10^{5} \mathrm{eggs} / \mathrm{m}^{2}\right)$ in the lake sediments (De Stasio 1989), and many of these eggs are quite old (mean age $70.4 \mathrm{yr}$, maximum age $330 \mathrm{yr}$; Hairston et al. 1995). We hypothesize that the pool of eggs of $D$. sanguineus present in the sediments of Bullhead Pond possesses a distribution of genotypes distinct from that expressed in the water column in any given year. 
The character upon which selection acts is the seasonal timing of the switch from immediately hatching eggs to diapausing eggs. For this copepod species, diapause timing is cued by a combination of photoperiod and temperature (Hairston and Olds 1986, Hairston et al. 1990, Hairston and Kearns 1995). Here we compare the egg-type distributions produced in response to photoperiod and temperature cues by female $D$. sanguineus drawn from copepods either hatched from the sediment egg bank, or from eggs produced by water-column individuals. We show that the mean timing of diapause differs significantly between these two subpopulations, but that the variances of egg bank and water-column copepods are similar. In addition, there are differences in the distribution of diapause between copepods hatched from young eggs obtained from near the sediment-water interface and copepods hatched from older eggs obtained from deeper in the sediment, as well as differences in diapause timing among copepods that hatch readily in the laboratory and those that take longer to respond to favorable hatching conditions. Our data appear to show covariance between time spent in diapause and seasonal timing of onset of diapause.

\section{Materials And Methods}

We measured the distributions of diapause timing in the laboratory by rearing copepods under photoperiods and temperatures chosen to mimic natural conditions near the time that the population of Diaptomus sanguineus naturally switches from producing immediately hatching eggs to diapausing eggs in Bullhead Pond. Our estimate of the distribution of switch dates is based on $9 \mathrm{yr}$ of data (Hairston 1987, Hairston and De Stasio 1988, Hairston and Kearns 1995). We determined the fraction of female copepods making either immediately hatching eggs or diapausing eggs at four photoperiod and temperature conditions: \pm 1.5 and \pm 2.5 standard deviations from the field mean (= day of year 85, 26 March). These values were chosen to maximize the statistical power of our analyses to detect differences in the variance of switch date between treatments (power estimated by Monte Carlo simulations over the expected range of variances based on previous studies of the diapause-timing distribution; Hairston and Dillon 1990). The standard deviation of switch date, though variable between years (Hairston and Dillon 1990), is $\approx 7 \mathrm{~d}$ (Hairston and Kearns 1995), thus the four laboratory environments followed day length and lake temperature conditions on day of year 67.5 (8 March), 74.5 (15 March), 95.5 (5 April), and 102.5 (12 April). The water temperatures were taken from averages of $11 \mathrm{yr}$ of data covering the chosen dates, using linear extrapolation between measurement dates when necessary. These temperatures were then matched to photoperiods obtained from standard tables. Combinations of photoperiod (to the nearest $15 \mathrm{~min}$ ) and temperature $\left( \pm 0.5^{\circ} \mathrm{C}\right)$ were created in four controlled environment chambers at $\left(\mathrm{L}: \mathrm{D} \times{ }^{\circ} \mathrm{C}\right): 11.75: 12.25 \times 4.3^{\circ}, 12.00$ :
$12.00 \times 6.0^{\circ}, 12.75: 11.25 \times 8.0^{\circ}$, and 13.25:10.75 $\times$ $10.5^{\circ}$. Illumination was provided by daylight fluorescent lamps (17-38 $\mu \mathrm{mol} \cdot \mathrm{s}^{-1} \cdot \mathrm{m}^{-2}$ depending upon location within the growth chamber).

Copepods active in the water column, and egg-containing sediments were collected on 2 March 1993 and 16 June 1993, respectively. Water-column animals (fifth instar copepodids) were obtained by plankton net before the population had begun to produce diapausing eggs. They were returned to the laboratory and 144 females were placed individually in 125 -mL glass jars, with two males per jar for mating, under short-day (L: $\mathrm{D}, 8: 16)$ and low temperature $\left(4.8^{\circ} \mathrm{C}\right)$ environments to ensure that all clutches produced were immediately hatching (Hairston and Olds 1986, 1987). One hundred twenty-one females became ovigerous over a $17-d$ period. An additional 82 egg-bearing females were obtained over the same period from the stock carboy in which plankton were transported from Bullhead Pond. All ovigerous females were isolated in filtered lake water in 7-mL wells of 12-well plastic tissue culture plates until their eggs had hatched.

Lake sediments were obtained from the lake center by scuba using six benthic core tubes $(16 \mathrm{~cm}$ diameter, $15 \mathrm{~cm}$ deep). In the laboratory, the top $5 \mathrm{~cm}$ of sediment was removed from each core in two layers (0-2 and $2-5 \mathrm{~cm}$ ), with each layer analyzed separately. We chose $5 \mathrm{~cm}$ as the maximum depth to analyze because viable egg density is substantially lower below $5 \mathrm{~cm}$ compared with that above (Hairston et al. 1995). We chose to divide the sediment at $2 \mathrm{~cm}$ because experiments using polystyrene beads (similar in size and specific gravity to diapausing eggs) show that the top $2 \mathrm{~cm}$ of the sediment at the center of Bullhead Pond is mixed to a modest extent by bioturbation (Kearns et al., in press, N. G. Hairston and C. M. Kearns, unpublished data), whereas deeper sediments are not. Moreover, radioisotope dating shows a steady decline in ${ }^{210} \mathrm{~Pb}$ activity throughout the top $10 \mathrm{~cm}$ with only a slightly steeper decline in the top $2-3 \mathrm{~cm}$ than deeper in the sediment (Hairston et al. 1995), again indicating modest mixing only in the top few centimetres. Within the $0-2 \mathrm{~cm}$ sediment layer there was a mean of $8.3 \times 10^{4}$ viable eggs $/ \mathrm{m}^{2}$, with a mean age of $12.2 \mathrm{yr}$; in the $2-5 \mathrm{~cm}$ layer there was a mean of $5.6 \times 10^{4}$ viable eggs $/ \mathrm{m}^{2}$, with a mean age of 56.7 yr old (De Stasio 1989, Hairston et al. 1995). Each sediment layer from each core was placed in a plastic tray (12 trays, each $38 \times 15 \times$ $5 \mathrm{~cm}$ ) for a sediment depth of $1.5-2.0 \mathrm{~cm}$ and glassfiber filtered Bullhead Pond water was siphoned over the top to bring total depth (sediment + water) in the trays to $4 \mathrm{~cm}$. The trays were incubated in a controlled environment chamber at $\mathrm{L}: \mathrm{D}, 13: 11$ and $15^{\circ} \mathrm{C}$. Each week for $52 \mathrm{wk}$, the water was siphoned out of each tray and checked for copepod nauplii. The filtered water was then returned to the trays and the sediment was thoroughly stirred before being allowed to stand undisturbed until the next siphoning. 
As they were obtained, nauplii from water column and sediment subpopulations were distributed evenly among the four environmental treatments. Nauplii were placed in 250-mL glass jars and fed laboratory-cultured Chlamydomonas sp., with more of this alga added every few days to keep culture jars slightly green. $E u$ glena gracilis was added to the diet when the animals reached the copepodid stage. For the water-column subpopulation, where groups of nauplii were obtained from individual clutches, siblings were reared one family per jar. Within each environmental chamber, the nauplii obtained from a particular sediment depth in a given week were reared together. Mature males and females were mated within each environmental treatment as previously described. Individual ovigerous females from these laboratory-reared cultures were again isolated in tissue culture wells and monitored daily for hatching. Eggs hatching within 2 wk (warm temperatures) or $4 \mathrm{wk}$ (cold temperatures) of laying were scored as immediately hatching eggs, those that had not hatched by this time and had not decomposed were scored as diapausing eggs (Hairston and Munns 1984, Hairston and Olds 1984, 1986).

Finally, in a preliminary study of diapause duration, a subset of the diapausing eggs produced by both watercolumn-derived and sediment-derived copepods were maintained in continuous dark and in a temperature regime similar to lake conditions. The eggs were held in their respective treatment temperatures for the first 3 to 5 wk post-production, after which they were cycled through summer $\left(13 \mathrm{wk}\right.$ at $\left.15^{\circ} \mathrm{C}\right)$, fall $\left(7 \mathrm{wk}\right.$ at $\left.8^{\circ} \mathrm{C}\right)$, and winter $\left(4^{\circ} \mathrm{C}\right)$ conditions, where they were held for the remainder of the experiment. Eggs were scored for hatching at intervals of $\approx 2-4 \mathrm{mo}$. The conditions do not strictly mimic the natural environment to which the eggs are exposed (except deep in the mud), but rather serve as an initial index by which the relative diapause duration of eggs from the two subpopulations can be compared. Eggs that had hatched were recognizable as either nauplii (live or dead), or as empty egg cases split along the equatorial seam that opens at the time of hatching (Champeau 1970).

\section{RESULTS}

Of the copepods collected from the water column, 832 females produced viable eggs. The proportions of females producing immediately hatching or diapausing eggs depended upon the photoperiod $\times$ temperature combination in which the copepods had been reared (Table 1). We analyzed these data, and other similar types of data discussed below, using Generalized Linear Interactive Modeling (GLIM) and accounted for potential overdispersion by allowing the program to estimate the scale parameter (Crawley 1993). Those copepods raised in early-season environments (short day, low temperature) produced a significantly greater fraction of immediately hatching eggs than did those
TABLE 1. Diapause response of Diaptomus sanguineus reared at four photoperiod $\times$ temperature combinations.

\begin{tabular}{|c|c|c|c|c|}
\hline & \multicolumn{4}{|c|}{$\begin{array}{c}\text { Treatment: } \\
\text { day length }(\mathrm{h}) \text { and temperature }\left({ }^{\circ} \mathrm{C}\right)\end{array}$} \\
\hline & $\begin{array}{r}11.75 \\
4.3^{\circ}\end{array}$ & $\begin{array}{r}12.00 \\
6.0^{\circ}\end{array}$ & $\begin{array}{r}12.75 \\
8.0^{\circ}\end{array}$ & $\begin{array}{l}13.25 \\
10.5^{\circ}\end{array}$ \\
\hline \multicolumn{5}{|l|}{ Water column } \\
\hline $\begin{array}{l}N \text { (clutches) } \\
\% \text { immediate }\end{array}$ & $\begin{array}{r}265 \\
91.3\end{array}$ & $\begin{array}{r}121 \\
74.4\end{array}$ & $\begin{array}{r}243 \\
12.8\end{array}$ & $\begin{array}{r}203 \\
2.0\end{array}$ \\
\hline \multicolumn{5}{|l|}{ Sediment } \\
\hline $\begin{array}{l}N \text { (clutches) } \\
\% \text { immediate } \\
0-2 \mathrm{~cm}\end{array}$ & $\begin{array}{l}84 \\
96.4\end{array}$ & $\begin{array}{r}106 \\
98.1\end{array}$ & $\begin{array}{r}345 \\
34.5\end{array}$ & $\begin{array}{r}354 \\
8.8\end{array}$ \\
\hline $\begin{array}{l}N \text { (clutches) } \\
\% \text { immediate } \\
2-5 \mathrm{~cm}\end{array}$ & $\begin{array}{l}49 \\
95.9\end{array}$ & $\begin{array}{l}50 \\
96.0\end{array}$ & $\begin{array}{r}205 \\
32.7\end{array}$ & $\begin{array}{r}170 \\
15.3\end{array}$ \\
\hline $\begin{array}{l}N \text { (clutches) } \\
\% \text { immediate }\end{array}$ & $\begin{array}{l}35 \\
97.1\end{array}$ & $\begin{array}{c}56 \\
100.0\end{array}$ & $\begin{array}{l}140 \\
37.1\end{array}$ & $\begin{array}{r}184 \\
2.7\end{array}$ \\
\hline
\end{tabular}

Note: Rows give numbers of viable clutches assayed for females reared from copepods obtained from the water column and from two sediment depths, and the percentage of those clutches that were immediately hatching eggs (\% immediate; as opposed to diapausing eggs).

reared in late season environments (GLIM; $F_{1,2}=$ 672.8, $P<0.005$ ).

In the laboratory, diapausing eggs hatched from the sediment trays for the entire period for which we monitored them $(363 \mathrm{~d}$ in $0-2 \mathrm{~cm}$ layer, $292 \mathrm{~d}$ in $2-5 \mathrm{~cm}$ layer). Although hatching was much reduced at the end of this period, it had not terminated (Fig. 1). A total of 9290 copepod nauplii $\left(7.70 \times 10^{4} / \mathrm{m}^{2}\right)$ were obtained from the $0-2 \mathrm{~cm}$ sediment trays, and 5768 nauplii $(4.78$ $\times 10^{4} / \mathrm{m}^{2}$ ) from the $2-5 \mathrm{~cm}$ trays. These numbers are strikingly close to estimates of mean egg densities (De Stasio 1989, Hairston et al. 1995; see Methods), and taken at face value imply $\approx 92$ and $85 \%$ hatching of the viable eggs from the $0-2$ and $2-5 \mathrm{~cm}$ sediments, respectively. From a random sample of these nauplii, 889 females produced viable clutches. As with watercolumn-derived copepods, there is a significant effect of environment (photoperiod $\times$ temperature) on egg type (Table 1; GLIM, $F_{1,2}=89.64, P<0.02$ ).

Does the phenotypic distribution of diapause response differ between copepods derived from the water column and those derived from the sediments? To answer this question, we pooled the results from the two sediment layers. Results from the $0-2$ and the $2-5 \mathrm{~cm}$ layers will be compared separately below. The distribution of clutch types differs significantly between the water-column-derived and the pooled sediment-derived copepods (GLIM; $F_{1.5}=24.82, P<0.005$ ). This significant effect results from a difference in distribution means rather than a difference in variances (Table 2, Fig. 2). Assigning the photoperiod $\times$ temperature treatments to the days of the year they mimic, maximum likelihood estimates of the means and standard deviations of switch-to-diapause dates were computed using an underlying Gaussian distribution for each population. 


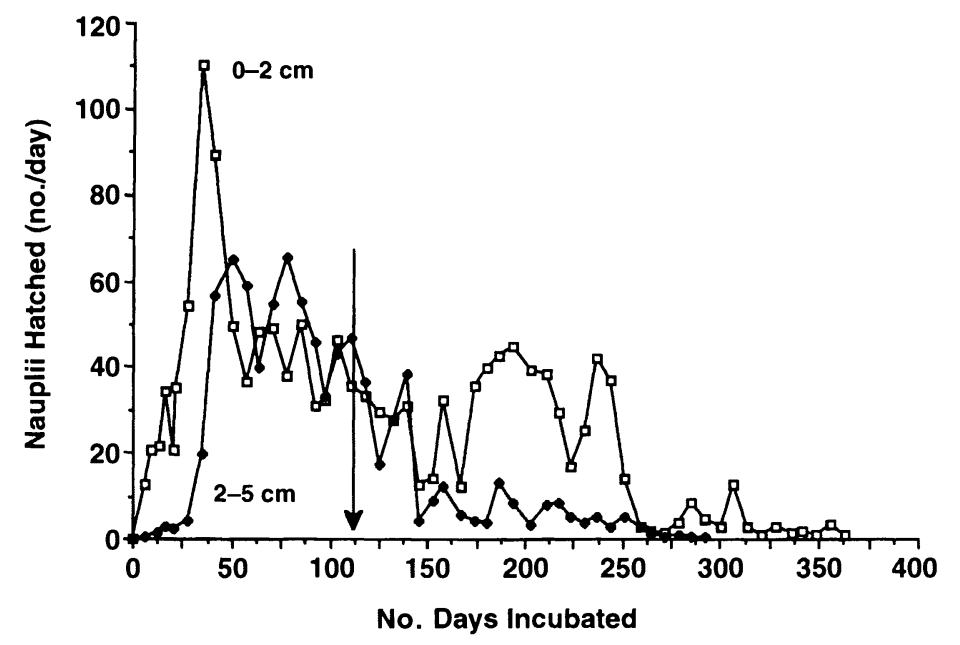

FIG. 1. Hatching rate of Diaptomus sanguineus nauplii (larval copepods) from diapausing eggs obtained from two layers of sediment $(0-$ $2 \mathrm{~cm}$ and $2-5 \mathrm{~cm}$ depth) collected from Bullhead Pond, Rhode Island. The arrow shows the point of the division at 8 October (day 111 of sediment incubation) between "early" and "late" hatching nauplii. See Results for further explanation and for methodological details.
Confidence intervals $(95 \% \mathrm{CI})$ were computed by bootstrapping from the data $\left(n=10^{4}\right.$ replicates). By this method, the mean date on which $D$. sanguineus from the water column switched to producing diapausing eggs is day 81.9 (23 March) whereas that for sediment copepods is day 90.4 (31 March). The means differ significantly (Table 2; 95\% Cis do not overlap), whereas the variances do not (standard deviation $95 \%$ CIS overlap).

There are subtle differences in the diapause response within the sediment-derived copepods. Maximum likelihood estimates of mean diapause timing did not differ significantly between copepods from the $0-2 \mathrm{~cm}$ layer (day 90.1) and copepods from the $2-5 \mathrm{~cm}$ layer (day 91.3) (Table 2; 95\% cis overlap). The phenotypic variance, however, is significantly lower in the $2-5 \mathrm{~cm}$

TABLE 2. Maximum likelihood estimates of the mean and standard deviation of diapause timing of Diaptomus sanguineus computed using an underlying Gaussian distribution for populations from the water column and sediments of Bullhead Pond, Rhode Island.

\begin{tabular}{lcccc}
\hline \hline \multirow{2}{*}{ Sample } & \multicolumn{4}{c}{ Switch date (day of year) } \\
\cline { 2 - 5 } & Mean & $95 \% \mathrm{Cl}$ & \multicolumn{1}{c}{ SD } & $95 \% \mathrm{CI}$ \\
\hline Water column & 81.9 & $80.6-83.1$ & 10.6 & $9.6-11.6$ \\
Sediment & & & & \\
$\quad \begin{array}{l}\text { Pooled }(0-5 \mathrm{~cm}) \\
0-2 \mathrm{~cm}\end{array}$ & 90.4 & $89.1-91.8$ & 9.4 & $7.8-10.7$ \\
$2-5 \mathrm{~cm}$ & 90.1 & $88.4-91.8$ & 11.4 & $9.3-13.5$ \\
$0-2 \mathrm{~cm}$ & 91.3 & $89.2-93.8$ & 6.9 & $4.0-8.8$ \\
$\quad$ early hatching & 92.3 & $90.5-94.1$ & 10.0 & $7.5-12.3$ \\
$\quad$ late hatching & 83.1 & $79.4-87.5$ & 9.7 & $6.3-13.2$ \\
$\begin{array}{c}\text { 2-5 cm } \\
\quad \text { early hatching }\end{array}$ & 92.5 & $90.9-93.9$ & 5.2 & $3.7-6.6$ \\
$\quad$ late hatching & 91.1 & $85.8-95.3$ & 12.2 & $1.8-20.6$ \\
\hline
\end{tabular}

Notes: The copepods were reared at four photoperiod $x$ temperature combinations that mimicked four dates during the spring when the copepods naturally switch from production of immediately hatching eggs to diapausing eggs. Confidence intervals $(95 \% \mathrm{CI})$ were computed by bootstrapping from the data $\left(n=10^{4}\right.$ replicates). copepods than in either the $0-2 \mathrm{~cm}$ copepods or the water-column-derived copepods (Table 2; 95\% Cis do not overlap).

We noticed while collecting our data that sedimentderived copepods from the $0-2 \mathrm{~cm}$ layer showed a distinct temporal pattern in diapause response that was absent in copepods from the $2-5 \mathrm{~cm}$ layer. Those that hatched early in the experiment were more likely to exhibit a later switch to diapause than were those that hatched late in the experiment (Table 2). This pattern can be seen most easily in the data for the laboratory environment simulating day of year 95.5 (see "sediment [pooled]" curve in Fig. 2) because in this data set an intermediate fraction of individuals made immediately hatching eggs. There is a distinct drop in the fraction of copepods that made immediately hatching

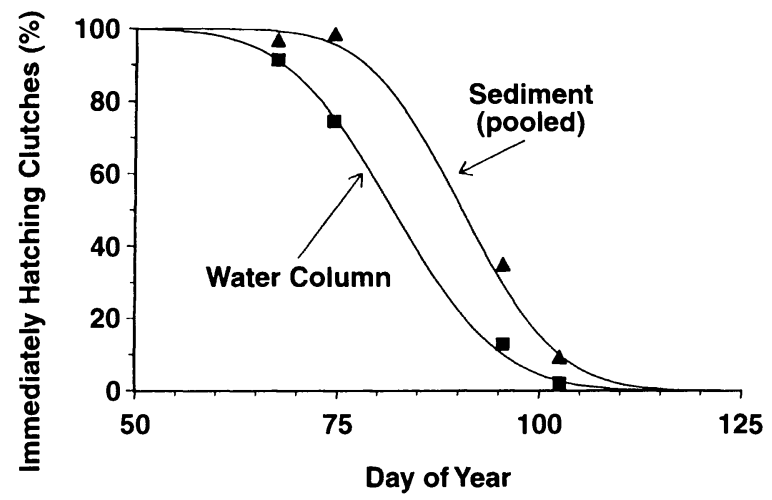

FIG. 2. Maximum likelihood Gaussian distributions fit to the diapause responses, expressed as fraction of females making egg clutches that hatch immediately (as opposed to diapause), of Diaptomus sanguineus from Bullhead Pond, Rhode Island. Response was determined for copepods reared from parents obtained directly from the water column of the lake or from diapausing eggs hatched from lake sediments. Four combinations of photoperiod and temperature that mimic the seasonal transition from winter to spring in the lake were used. January 1 was day 1 . 


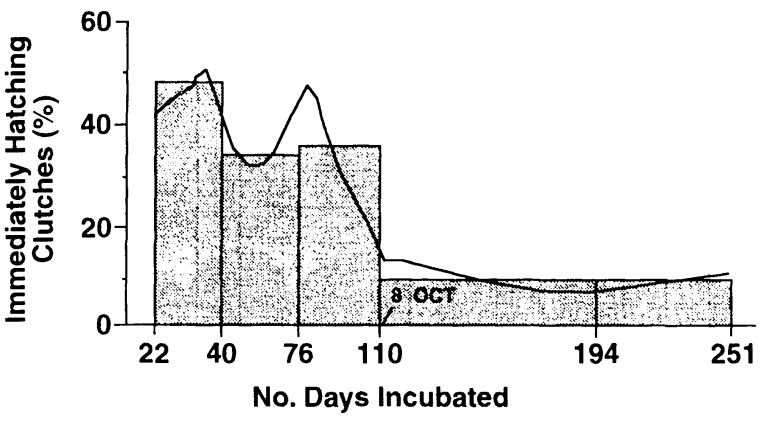

FIG. 3. The fraction of copepods $(N=205$ inds. $)$ hatched from Bullhead Pond sediment $(0-2 \mathrm{~cm}$ depth) that made immediately hatching eggs in a $12.75: 11.25(\mathrm{~L}: \mathrm{D})$ and $8.0^{\circ} \mathrm{C}$ environment (simulates day 95.5 of year; January 1 was day 1) as a function of the length of time that eggs in the experiment were exposed to hatching conditions. Two presentations of the same data are given. The continuous line shows a locally weighted regression scatterplot smoothing with a distinct drop at 8 October. The histogram bars divide the data into five time intervals for statistical analysis: the first three intervals differ significantly from the last two (see Results).

eggs in this environment among those that hatched before early October and those that hatched later (Fig. 3). "Lowess" (locally weighted regression scatterplot smoothing) analysis (Velleman 1995) of the data shows a distinct drop in the fraction of copepods making immediately hatching eggs in early October. For further analysis, we divided the data into five intervals of roughly equal sample size (interval duration varied [Fig. 3] because more copepods hatched early as opposed to late in the experiment, Fig. 1). Among the first three intervals, copepods did not differ significantly in proportion producing immediately hatching eggs (GLIM likelihood ratio test; $G^{2}=2.50$, $\mathrm{df}=2$, NS). Likewise, among the last two intervals, copepods did not differ significantly in proportion producing immediately hatching eggs (GLIM likelihood ratio test; $G^{2}=0.00, \mathrm{df}=2$, Ns). There is, however, significant variation among all groups (GLIM likelihood ratio test; $\left.G^{2}=24.66, \mathrm{df}=4, P<0.005\right)$. When we divide all of the data from all four photoperiod $\times$ temperature environments (cf. Table 1) into "early-hatching" copepods and "late-hatching" copepods using early October (8 October, Julian day 281) to divide between the two groups there is a significant difference in diapause response (GLIM allowing for overdispersion; $F_{1.5}=$ 18.75, $P<0.01)$. The mean switch dates for the $0-2$ $\mathrm{cm}$ copepods are day 92.3 for the copepods that hatched early in the experiment and day 83.1 for the copepods that hatched late, and the $95 \%$ confidence intervals do not overlap (Table 2).

An early October division of the data makes sense biologically. The $D$. sanguineus in Bullhead Pond switch each year to making diapausing eggs in late March (Hairston and Munns 1984). In the laboratory, under ideal hatching conditions, newly produced diapausing eggs began to hatch only after a period of 6 mo (N. G. Hairston, Jr. and C. M. Kearns, unpublished data, B. T. De Stasio, Jr., personal communication). Six months after the end of March is the beginning of October, which is close to the time when $D$. sanguineus diapausing eggs begin to hatch in Bullhead Pond each year (Hairston and Munns 1984). Thus our early group consists only of copepods that hatched from eggs laid in years prior to 1993; our late group includes copepods that hatched from eggs laid after the population switched to making diapausing eggs in March 1993.

For the $2-5 \mathrm{~cm}$ data, early-hatching and late-hatching copepods did not differ significantly in diapause response (GLIM allowing for overdispersion, $F_{1.5}=$ $0.05, P \gg 0.75)$. The mean switch dates for the $2-5$ $\mathrm{cm}$ copepods are day 92.5 early-hatching copepods and day 91.1 for the late-hatching copepods; the $95 \%$ confidence intervals overlap markedly (Table 2 ).

The diapausing eggs collected from the water-column-derived and the sediment-derived copepods began to hatch after different periods in diapause (Fig. 4), even though the two groups were maintained under identical conditions. Diapausing eggs from the watercolumn-derived copepods began hatching within 7 mo after they were laid. In contrast, diapausing eggs from the sediment-derived copepods did not begin to hatch in significant numbers until $>12$ mo after they were laid. Only $\approx 45 \%$ of the eggs had hatched 20 mo after the experiment started, with a low but steady hatching rate in both subpopulations. Again, we do not believe that the quantitative details of the hatching phenology are relevant to field conditions: we wish here only to emphasize that the timing of initiation of hatching differs between the subpopulations (Gehan's test, $z=$ 7.08, $P \ll 0.001, n=1279$; Gross and Clark 1975).

\section{Discussion}

The timing of the switch to diapause in March or April is an important fitness character for Diaptomus sanguineus in Bullhead Pond. It dictates the vulnerability of a female's progeny to annual springtime in-

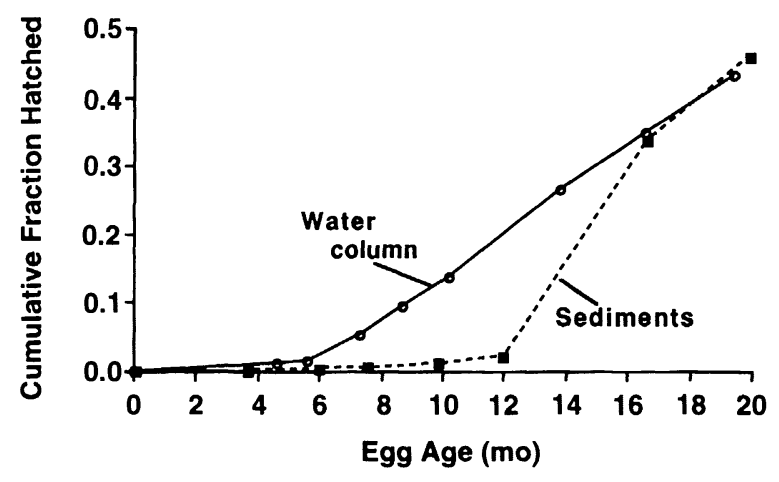

FIG. 4. The fraction of viable diapausing eggs laid by the water-column-derived and the sediment-derived copepods hatching over a period of $20 \mathrm{mo}$. Eggs from the water-column subpopulation tend to hatch after a shorter period of diapause than do eggs from the sediment subpopulation. 
creases in fish predation (Hairston and Munns 1984, Hairston 1987), and hence directly impacts her representation in future generations. Copepods that switch from making immediately hatching eggs to diapausing eggs too late in the season lose fitness because some of their offspring get eaten before they can mature. Those that switch too early in the season lose representation in future generations because their offspring lose time to mature and to make diapausing eggs of their own. We have shown that there are distinct differences in the phenotypic expression of diapause timing depending upon whether the copepods originated from the active subpopulation in the water column or from the diapausing subpopulation in the sediment. Within the sediment subpopulation, there are further differences depending both upon whether the copepods were hatched from diapausing eggs obtained from near the sediment surface $(0-2 \mathrm{~cm})$ or from deeper sediments $(2-5 \mathrm{~cm})$, and upon whether the copepods came from sediment diapausing eggs that readily hatched (i.e., early in the egg hatching experiment) or from eggs that were slower to hatch. In addition, the water-column and sediment subpopulations differ in the time between when eggs are laid and when they begin to hatch.

Do these phenotypic patterns have an important genetic component? We suspect that the answer is yes, but we cannot rule out an important plasticity component. In laboratory breeding experiments, diapause photoperiod response in $D$. sanguineus had a significant heritability $\left(h^{2}=0.48\right.$, Hairston and Dillon 1990). In the field, the mean timing of diapause for this species shifted between years in a pattern consistent with interannual variation in the timing and intensity of the seasonal onset of fish predation in both the Bullhead Pond population (Hairston and Dillon 1990) and in a nearby population in Little Bullhead Pond (Hairston and Walton 1986, Hairston and De Stasio 1988), demonstrating that diapause timing is also heritable in the field. The copepods in our experiment were all reared from eggs in the laboratory using a "common garden" experimental design, and the differences in diapause response we have documented describe consistent patterns across photoperiod $\times$ temperature treatments and among subpopulations. These arguments provide circumstantial evidence for heritable differences in diapause timing between the sediment and water-column subpopulations of $D$. sanguineus in Bullhead Pond.

Our hypothesis at the start of this research was that fluctuating selection on the timing of diapause combined with prolonged egg diapause would lead to the storage of higher levels of trait variation among diapausing eggs in the sediment than would be expressed at any one time by copepods active in the water-column. This is clearly not the case. Phenotypic variances are remarkably similar between these groups (Table 2, water column vs. pooled sediment). Instead, the really striking difference between the subpopulations is in the mean timing of diapause. Copepods derived from dia- pausing eggs ranging in age (Hairston et al. 1995) from 0 to $76 \mathrm{yr}$ (i.e., $0-5 \mathrm{~cm}$ ) on average switch to diapause 9-10 d later than copepods derived from animals swimming in the water column.

Is there a plausible explanation for this difference in diapause timing between the water-column and sediment subpopulations? One obvious possibility is that there has been recent directional natural selection favoring an earlier switch to diapause. Because diapause timing in Bullhead Pond is known to be an adaptation to avoid the seasonal onset of fish predation (see Introduction for details; Hairston 1987, Hairston and Dillon 1990), a change to an earlier seasonal diapause would have occurred if the fish predation had increased markedly in the recent past. We have, in fact, observed the opposite of such a response: $2 \mathrm{yr}$ after fish were completely eliminated from Little Bullhead Pond (200 $\mathrm{m}$ from Bullhead Pond) by a single-year drought, the mean timing of diapause shifted to later in the spring by $26 \mathrm{~d}$ (Hairston and Walton 1986). In Bullhead Pond, however, we know that changes in selection of this magnitude have not occurred in at least the past decade. Selection on diapause timing of $D$. sanguineus has been quantified in Bullhead Pond in nine separate years between 1979 and 1989 (Hairston and Dillon 1990, S. Ellner and N. G. Hairston, Jr., unpublished manuscript). This is approximately the same period covered by the top centimetre of sediment (Hairston et al. 1995). Between 1979 and 1989, selection fluctuated but showed no consistent directionality. The average magnitude of the change in diapause timing between consecutive years was $2.47 \mathrm{~d}$, with a total change over the entire period (1979-1989) of $2.17 \mathrm{~d}$. Since 1989, there have been no obvious directional changes in fish abundance or in the volume of water in Bullhead Pond (decrease in volume translates into an increase in fish density, Hairston 1988) that would have caused an alteration in selection pressure sufficient to produce the 9- or 10-d difference in diapause timing between the sediment and water-column subpopulations (N. G. Hairston, Jr., personal observation). The top two centimetres of sediment do contain eggs laid up to $28 \mathrm{yr}$ ago, $17 \mathrm{yr}$ before the period for which we have direct evidence of copepod and fish dynamics. However, changes in fish predation in Bullhead Pond are related directly to changes in pond volume (Hairston 1988), which are in turn a function of changes in water table height, which has shown no trend since 1948 when the U.S. Geological Survey first began collecting data near Bullhead Pond (Hairston 1988). In addition, if the nature of fish predation had changed prior to 1979 , we would have predicted an impact on the mean and variance of diapause timing for copepods drawn from the $0-2 \mathrm{~cm}$ sediment layer relative to either the water-column copepods or to those from the deeper sediment layer because the time period encompassed by the $0-2 \mathrm{~cm}$ sediment layer would span the period of directional se- 
lection and response. We observed no such effect (Table 2).

With recent selection response ruled out, we hypothesize that the differences in diapause timing between sediment and water-column subpopulations are due to a covariance between diapause traits expressed in eggs and adults. Specifically, there is covariance, possibly genetic, between adult "switch date" (the day of the year when an adult switches from making immediately hatching eggs to making diapausing eggs), and the propensity of an egg to remain dormant for an extended time in the sediment.

Two lines of evidence support this covariance hypothesis. First, diapausing eggs produced by water-column-derived adults with an early switch date tend to hatch sooner than eggs produced by sediment-derived adults with a late switch date (cf. Figs. 2 and 4). Second, early switch date is observed in two groups of copepods: those in the water column, and those eggs from the surface sediments $(0-2 \mathrm{~cm})$ that take a long time to hatch (Table 2). We know that there is a 6-mo period before new eggs can hatch (Fig. 4), hence the late-hatching subpopulation includes some eggs produced in the previous year, while the early-hatching subpopulation consists entirely of eggs that were produced in prior years and remained in diapause. The latter eggs grow up to have the later mean switch date (Table 2). Thus the subset of eggs that are known to have remained in diapause for $>1$ yr have a later-thanaverage switch date, which again indicates a covariance between egg diapause and adult switch date. We give a possible explanation for this trait association below, but first we suggest two ways in which this trait association might be maintained: phenotypic plasticity and genetic covariance.

Under phenotypic plasticity, either the timing of the switch to diapause or the timing of egg hatching, or both, must be affected in a repeatable way by some environmental factor. For example, if there is genetic variation for the timing of the onset of diapause (as shown by Hairston and Dillon 1990) and diapause duration is influenced by the time of year the diapausing egg is produced (postulated here for the sake of argument), then the trait association we observe could be produced. Another possibility is that the age at which a diapausing egg hatches affects diapause timing of the resulting copepod. The environmental cue to hatch is a function of light, oxygen, and probably temperature (N. G. Hairston, Jr. and C. M. Kearns, unpublished data). Those eggs near the sediment-water interface are likely to receive the hatching cue whereas those buried deeper in the sediment almost certainly do not receive it (hence they hatched in our study only when we gave them the appropriate cue in the laboratory; Fig. 1). If an egg becomes buried in the sediment before receiving the hatch cue, aging might affect how it responds to the water-column environment once it does hatch. Most of our data would be explained if eggs that receive the cue within the first year (i.e., offspring collected directly from the water column, or young eggs from the surface of the $0-2 \mathrm{~cm}$ layer) tend to switch to diapause early in the season, whereas eggs that have been in the sediment for multiple years (i.e., from deeper in the sediment) tend to switch to diapause later in the season. One piece of our data is not, however, consistent with this interpretation. Water-columnderived copepods that switched to diapause early in the season made diapausing eggs that tended to begin hatching in the laboratory after only $6 \mathrm{mo}$; sedimentderived copepods that switched to diapause late in the season made diapausing eggs that tended to begin hatching in the laboratory after 12 mo (Fig. 4). Thus it was not egg age that determined when the copepods switched to diapause, but rather when the copepods switched to diapause that determined the timing of hatching. One would have to add another layer of complexity (i.e., a maternal effect of timing of switch to diapause on duration of egg diapause) in order to maintain this phenotypic plasticity hypothesis.

An alternative explanation for the trait association is that there is genetic determination of diapause timing (Hairston and Dillon 1990) and duration of diapause in the sediment (which has not yet been shown, and is only hypothesized here). If copepods that are genetically predisposed to hatch within the $1 \mathrm{st}$ yr after being produced also tend to have genes that dictate an early seasonal switch to diapause, while those that are genetically predisposed to hatch after a longer period of time also tend to have genes that dictate a late switch to diapause, we could account for all of our current data. Genetic covariance of this sort would need to be tested in controlled breeding experiments in the laboratory.

We conclude our discussion with an hypothesis that would explain the trait association we observe whether it is maintained by phenotypic plasticity or genetic covariance. We hypothesize that there may be two alternative adaptive strategies for a copepod to persist in the temporally variable environment of Bullhead Pond. In both, diapause is an important short-term adaptation for avoiding seasonally intense predation, but its value as a long-term persistence mechanism differs. One strategy is for nearly all diapausing eggs to hatch the year after they are produced. This is a potentially risky long-term strategy because any year with an early and intense onset of fish predation could lead to little or no recruitment of these short-diapause-duration copepods. The risk can be countered, however, if individuals also possess an early seasonal switch to diapause; that is, a safe diapause timing strategy. We call this first approach the "risky-in-the-sediment/safe-in-the-watercolumn" strategy. The alternative strategy is for only a small fraction of the diapausing eggs produced in any given year to hatch in any single subsequent year. This is a relatively safe long-term strategy in that years of poor or zero recruitment are survived by the diapausing 
eggs that did not hatch. Eventually, when a good-recruitment year comes, the egg bank is restocked. Copepods that adopt this "safe-in-the-sediment" strategy should wait until relatively late in the season to switch to diapause (i.e., a risky diapause timing strategy) because they rely on occasional good-recruitment years. The later the switch date, the higher the recruitment (because the population grows larger before producing diapausing eggs) and the higher the fitness of the copepods until the seasonal increase in fish predation terminates the reproductive season. We call the second approach a "safe-in-the-sediment/risky-in-the-watercolumn" strategy.

Our hypothesis, then, proposes the evolution of trait covariance between duration of egg diapause in the lake sediments and diapause timing by copepods active in the water column. That association could be maintained either by phenotypic plasticity or genetic covariance. The proposal differs qualitatively from what Evans and Cabin (1995) suggest for plant seed banks in that they postulate the evolution of particular genotypes that germinate in years with particular types of environments (which then evolve covariance with genotypes for postgermination performance in those environments). In contrast, our hypothesis proposes that some phenotypes spend a short time in diapause whereas others spend a long and variable time in diapause regardless of what type of environment is present in any given year (but which also leads to evolution of covariation with posthatch performance in particular types of years). The postulated risky-safe/safe-risky corresponds to Levins' (1979) model of coexistence between strategies specializing on the mean and variance in a fluctuating environment. The risky-in-the-sediments individuals mostly have a switch date near to the optimal one in the mean environment, while later and riskier switch dates predominate among the safe-in-the-sediments individuals.

A simple genetic model based on Ellner and Hairston (1994) suggests that the risky-safe/safe-risky strategy pair are a natural result of selection in this system. Details of this model will be presented elsewhere, and we present a brief overview here only to point out that a model can produce the trait associations we observe. The essential ingredients of the model are generation overlap, fluctuating selection on switch date, and heritable variation in both switch date and the annual hatching fraction of diapausing eggs. The model predicts that when the variance in the optimal switch date is low, all individuals are risky-safe: a high hatching fraction and a safe, early switch date. At higher variance, a dimorphism for hatching fraction develops: some individuals become safe-risky (lower hatching fraction associated with a later switch date). The saferisky and risky-safe strategies cannot out-compete each other, but they collectively out-compete any other strategy. This specific outcome depends on there being a substantial "pay-off" for late switching in years when
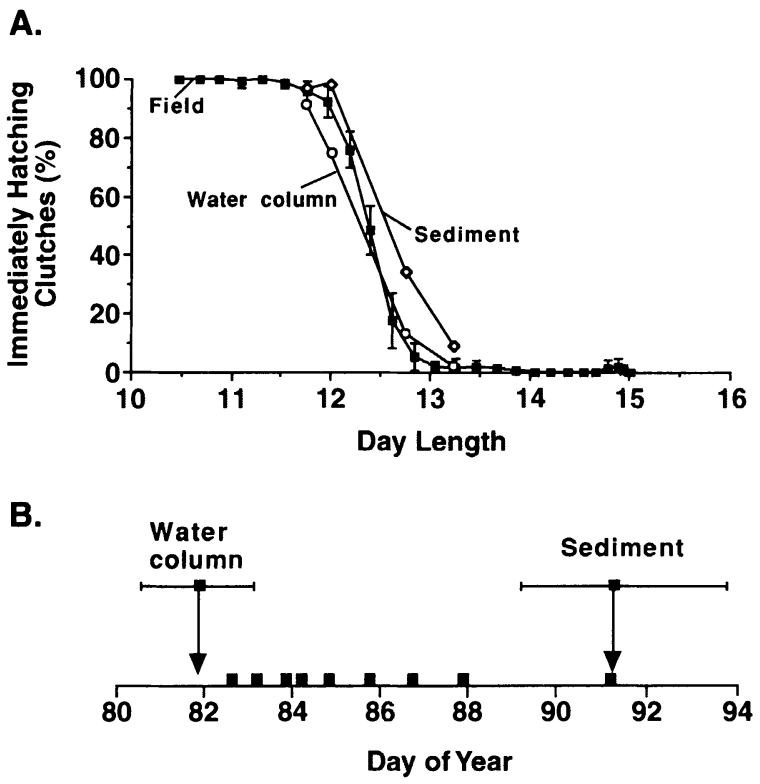

FIG. 5. The timing of diapause of Diaptomus sanguineus in Bullhead Pond, Rhode Island, lies intermediate between subpopulations obtained from the lake water column and the lake sediments. (A) The fraction of immediately hatching eggs produced in the field (closed squares) as day length increases in spring (mean and 95\% CI, $n=9 \mathrm{yr}$ ), and the diapause responses of copepods reared in the laboratory from parents obtained directly from the water column of the lake (open circles) or from diapausing eggs hatched from lake sediments (open diamonds). Laboratory results are for four combinations of photoperiod and temperature that mimic the seasonal transition from winter to spring in the lake. (B) The mean timing of diapause in each of nine years in the lake in relation to the mean timing observed for the "water-column" and "sediment" (2-5 cm depth) subpopulations.

the optimal switch date is late. Other outcomes are possible under different assumptions about the selection regime.

If two strategies (i.e., safe-risky and risky-safe) coexist in the Bullhead Pond population of D. sanguineus, then the average diapause phenology expressed by the copepods in the lake should fall somewhere between these two extremes. This is the case (Fig. 5A). The distribution of mean diapause timing over the $9 \mathrm{yr}$ for which we have data (Hairston and Dillon 1990, S. Ellner and N. G. Hairston, Jr., unpublished manuscript) is distinctly skewed towards early switch dates, but with a tail extending to later dates (Fig. 5B). To illustrate where these mean switch dates lie relative to the dates we report here for the water-column and sediment subpopulations, we use the means and $95 \%$ confidence intervals from Table 2. The mean switch dates for all $9 \mathrm{yr}$ lie between the extremes of the water-column and sediment $(2-5 \mathrm{~cm})$ subpopulations, consistent with the interpretation that each year contains a mixture of the phenotypes present in the two subpopulations. Much of the year-to-year variation in mean switch date can be ascribed to selection response (Hairston and Dillon 
1990, S. Ellner and N. G. Hairston, Jr., unpublished manuscript), but some may also result from expression of varying proportions of the "water-column" and "sediment" phenotypes. In most years, the switch to diapause came relatively early, close to, but in only one case overlapping with, the $95 \%$ confidence interval of the diapause timing in the water-column subpopulation. Only in 1981 did the mean timing of diapause fall close to the sediment diapause timing. In that year, Bullhead Pond was extremely shallow (Hairston 1988) due to the same drought that dried up Little Bullhead Pond. Most of the D. sanguineus egg bank in Bullhead Pond is in sediments near the center of the lake rather than in near-shore sediment (De Stasio 1989). It seems likely, then, that when water level dropped during the 1981 drought, deep sediments were disturbed by physical (i.e., wave action) and biological (i.e., fish nesting) processes usually restricted to near the shore. These deep sediments contain the store of risky-in-the-watercolumn/safe-in-the-sediment phenotypes, which when introduced into the water column in large numbers cause the unusual shift in the mean timing of diapause to very late in the season that we observed in 1981 .

Long-lived dormant propagule pools such as the crustacean egg bank that we have investigated have long been suspected of containing stored genetic variation that might have significant impacts on ecological and evolutionary processes (e.g., Epling et al. 1960, Templeton and Levin 1979, Brown and Venable 1986). Our data provide clear evidence that phenotypic (and presumably genotypic) differences exist for an important fitness character (timing of diapause) between subpopulations of the copepod $D$. sanguineus active in the water column and those residing in diapause in the sediments of Bullhead Pond. This means that phenotypic variance for this trait in the total population (active and diapausing individuals) is substantially greater than that expressed in either of the subpopulations. Furthermore, both the overall population mean and variance are different from what they would be in the absence of an egg bank. A major portion of the variance we see apparently results from covariance between duration of diapause in the egg bank and the fitness character under investigation. This complicates in interesting ways the role that dormant propagule pools may play in natural populations. Not only may they act as a reservoir of genotypes produced in past environments, but they may interact as a part of the selectionresponse dynamics of current environment in ways that can slow down response to selection, speed it up, or alter its direction.

\section{ACKNOWLEDGMENTS}

We thank Keith O. Batson and Katherine M. Dowell for technical assistance in the laboratory and Charles McCulloch for statistical advice. Saran Twombly and her lab group monitored copepod population development in Bullhead Pond and advised us when to make our collecting trips to Rhode Island. Steven A. Juliano and two referees provided valuable criti- cism of the manuscript. This research was supported by National Science Foundation grant DEB-9119984.

\section{Literature Cited}

Bennington, C. C., J. B. McGraw, and M. C. Vavrek. 1991. Ecological genetic variation in seed banks. II. Phenotypic and genetic differences between young and old subpopulations of Luzula parviflora. Journal of Ecology 79:627643.

Bosbach, K., H. Hurka, and R. Haase. 1982. The soil seed bank of Capsella bursapastoris (Cruciferae): its influence on population variability. Flora 172:47-56.

Brown, J. S., and D. L. Venable. 1986. Evolutionary ecology of seed-bank annuals in temporally varying environments. American Naturalist 127:31-47.

Champeau, A. 1970. Etude de la vie latente chez les Calanoïdes (Copépodes) caractéristiques des eaux temporaires de Basse-Provence. Annales de la Faculté des Sciences de Marseille 44:155-189.

Chesson, P. L. 1984. The storage effect in stochastic population models. Lecture Notes in Biomathematics 54:7689.

Crawley, M. J. 1993. GLIM for ecologists. Blackwell Scientific, New York, New York, USA.

De Stasio, B. T., Jr. 1989. The seed bank of a freshwater crustacean: copepodology for the plant ecologist. Ecology 70:1377-1389.

Ellner, S., and N. G. Hairston, Jr. 1994. Role of overlapping generations in maintaining genetic variation in a fluctuating environment. American Naturalist 143:403-417.

Epling, C., H. Lewis, and F. M. Ball. 1960. The breeding group and seed storage: a study in population dynamics. Evolution 14:238-255.

Evans, A. S., and R. J. Cabin. 1995. Can dormancy affect the evolution of post-germination traits? The case of Lesquerella fendleri. Ecology 76:344-356.

Futuyma, D. J. 1986. Evolutionary biology. Sinauer, Sunderland, Massachusetts, USA.

Gottlieb, L. D. 1974. Genetic stability in a peripheral isolate of Stephanomeria exigua ssp. coronaria that fluctuates in population size. Genetics 76:551-556.

Gross, A. J., and V. A. Clark. 1975. Survival distributions: reliability applications in the biomedical sciences. John Wiley and Sons, New York, New York, USA.

Hairston, N. G., Jr. 1987. Diapause as a predator avoidance adaptation. Pages 281-290 in W. C. Kerfoot and A. Sih, editors. Predation: direct and indirect impacts on aquatic communities. New England University Press, Hanover, New Hampshire, USA.

-1988. Interannual variation in seasonal predation: its origin and ecological importance. Limnology and Oceanography 33:1245-1253.

Hairston, N. G., Jr., and B. T. De Stasio, Jr. 1988. Rate of evolution slowed by a dormant propagule pool. Nature 336: 239-242.

Hairston, N. G., Jr., and T. A. Dillon. 1990. Fluctuating selection and response in a population of freshwater copepods. Evolution 44:1796-1805.

Hairston, N. G., Jr., T. A. Dillon, and B. T. De Stasio, Jr. 1990. A field test for the cues of diapause in a freshwater copepod. Ecology 71:2218-2223.

Hairston, N. G., Jr., S. Ellner, and C. M. Kearns. 1996. Overlapping generations: the storage effect and the maintenance of biotic diversity. Pages 109-145 in O. E. Rhodes, Jr., R. K. Chesser, and M. H. Smith, editors. Spatial and temporal aspects of population processes. University of Chicago Press, Chicago, Illinois, USA.

Hairston, N. G., Jr., and C. M. Kearns. 1995. The interaction of photoperiod and temperature in diapause timing: a copepod example. Biological Bulletin (Woods Hole) 189:4248. 
Hairston, N. G., Jr., and W. R. Munns, Jr. 1984. The timing of copepod diapause as an evolutionarily stable strategy. American Naturalist 123:733-751.

Hairston, N. G., Jr., and E. J. Olds. 1984. Population differences in the timing of diapause: adaptation in a spatially heterogeneous environment. Oecologia (Berlin) 61:42-48.

Hairston, N. G., Jr., and E. J. Olds. 1986. Partial photoperiod control of diapause in three populations of the freshwater copepod Diaptomus sanguineus. Biological Bulletin (Woods Hole) 171:135-142.

Hairston, N. G., Jr., and E. J. Olds. 1987. Population differences in the timing of diapause: a test of hypotheses. Oecologia (Berlin) 71:339-344.

Hairston, N. G., Jr., R. A. Van Brunt, C. M. Kearns, and D. R. Engstrom. 1995. Age and survivorship of diapausing eggs in a sediment egg bank. Ecology 76:1706-1711.

Hairston, N. G., Jr., and W. E. Walton. 1986. Rapid evolution of a life history trait. Proceedings of the National Academy of Sciences (USA) 83:4831-4833.

Kearns, C. M., N. G. Hairston, Jr., and D. H. Kesler. 1996. Particle transport by benthic invertebrates: its role in egg bank dynamics. Hydrobiologia, in press.

Kimura, M. 1983. The neutral theory of molecular evolution. Cambridge University Press, Cambridge, England.

Levins, R. 1979. Coexistence in a variable environment. American Naturalist 114:765-783.

McGraw, J. B. 1993. Ecological genetic variation in seed banks: IV. Differentiation of extant and seed bank-derived populations of Eriophorum vaginatum. Arctic and Alpine Research 25:45-49.

McGraw, J. B., M. C. Vavrek, and C. C. Bennington. 1991. Ecological genetic variation in seed banks: I. Establishment of a time transect. Journal of Ecology 79:617-625.

Rees, M. 1994. Delayed germination of seeds: a look at the effects of adult longevity, the timing of reproduction, and population age/stage structure. American Naturalist 144: 43-64.

Seger, J., and H. J. Brockmann. 1987. What is bet-hedging? Oxford Surveys in Evolutionary Biology 4:182-211.

Templeton, A. R., and D. A. Levin. 1979. Evolutionary consequences of seed pools. American Naturalist 114:232249.

Tonsor, S. J., S. Kalisz, J. Fisher, and T. P. Holtsford. 1993. A life-history based study of population genetic structure: seed bank to adults in Plantago lanceolata. Evolution 47: 833-843.

Vavrek, M. C., J. B. McGraw, and C. C. Bennington. 1991. Ecological genetic variation in seed banks. III. Phenotypic and genetic differences between young and old seed populations of Carex bigelowii. Journal of Ecology 79:645662.

Velleman, P. F. 1995. Data desk, version 5.0, statistics guide. Data Description, Ithaca, New York, USA.

Wolf, H. G., and G. R. Carvalho. 1989. Resting eggs of lakeDaphnia II. In situ observations on the hatching of eggs and their contribution to population and community structure. Freshwater Biology 22:471-478. 